This item was submitted to Loughborough's Research Repository by the author.

Items in Figshare are protected by copyright, with all rights reserved, unless otherwise indicated.

\title{
Enhanced Fault Tree analysis and modelling considerations of a Polymer Electrolyte Membrane Fuel Cell
}

PLEASE CITE THE PUBLISHED VERSION

http://www.balkema.nl/

PUBLISHER

CRC Press / Balkema (@ Taylor \& Francis Group)

VERSION

AM (Accepted Manuscript)

LICENCE

CC BY-NC-ND 4.0

REPOSITORY RECORD

Whiteley, Michael, L.M. Bartlett, and Sarah J. Dunnett. 2014. "Enhanced Fault Tree Analysis and Modelling Considerations of a Polymer Electrolyte Membrane Fuel Cell”. figshare. https://hdl.handle.net/2134/14204. 
This item was submitted to Loughborough's Institutional Repository (https://dspace.lboro.ac.uk/) by the author and is made available under the following Creative Commons Licence conditions.

\section{creative
commons}

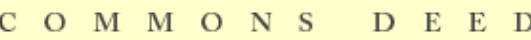

Attribution-NonCommercial-NoDerivs 2.5

You are free:

- to copy, distribute, display, and perform the work

Under the following conditions:

Attribution. You must attribute the work in the manner specified b the author or licensor.

Noncommercial. You may not use this work for commercial purposes.

No Derivative Works. You may not alter, transform, or build upon this work.

- For any reuse or distribution, you must make clear to others the license terms of this work.

- Any of these conditions can be waived if you get permission from the copyright holder.

Your fair use and other rights are in no way affected by the above.

This is a human-readable summary of the Leqal Code (the full license).

\section{Disclaimer 만}

For the full text of this licence, please go to: http://creativecommons.org/licenses/by-nc-nd/2.5/ 


\title{
Enhanced Fault Tree Analysis and Modelling Considerations of a Polymer Electrolyte Membrane Fuel Cell
}

\author{
M. Whiteley, L. Bartlett \& S. Dunnett \\ Department of Aeronautical and Automotive Engineering, \\ Risk and Reliability Research Group, \\ Loughborough University, \\ Loughborough, \\ UK
}

\begin{abstract}
With the recent increase in interest in environmental issues and climate change concerns, the scientific community have been tasked with developing low carbon technologies to mitigate against climate change. One of the most promising technologies is the hydrogen fuel cell, particularly when integrated into an automobile. Hydrogen Fuel Cells are an electro-chemical, zero-emission energy conversion and power generation device. Their only output products are heat, electrical energy, and water vapour.

There are three main hurdles to the commercial uptake of this technology; Infrastructure, Cost and Reliability. An understanding of the reliability of fuel cells can be obtained through in-depth reliability analysis including techniques such as Failure Mode and Effect Analysis (FMEA) and Fault Tree analysis (FTA) amongst others. As hydrogen fuel cells are a relatively new technology this in-depth analysis is still in its infancy, and needs development. This research has extended the work on FTA of the Polymer Electrolyte Membrane Fuel Cell (PEMFC) systems. Detailed analysis has explored the inherent complexity of the PEMFC system where issues with using a basic FTA for a PEMFC, such as dependencies between failure modes, and disparities between failure mode operating principles, are discussed. The integration of the Markov technique, which can deal with dependencies, within the Fault tree approach is suggested as a mechanism to enhance the accuracy of the modelling of a PEMFC.
\end{abstract}

\section{INTRODUCTION}

\subsection{The need for fuel cells}

Climate change issues and sustainability concerns have increased in interest and awareness in recent years, since anthropogenic activities have been found to impact considerably upon the environment (Solloman, 2007). The way in which manmade activities contribute to climate change is mainly due to greenhouse gas (GHG) emissions. These include, among others, carbon dioxide $\left(\mathrm{CO}_{2}\right)$, methane $\left(\mathrm{CH}_{4}\right)$ and nitrous oxide $\left(\mathrm{N}_{2} \mathrm{O}\right)$ that contribute to the greenhouse effect. Additionally, energy prices are set to continue to rise by alarming rates (BERR, 2010) which will disrupt the UK's energy system due to a rise in oil prices. The UK emitted 549.3 Million tonnes of Carbon Dioxide equivalent $\left(\mathrm{MtCO}_{2} \mathrm{e}\right)$ in 2011 (DECC, 2011) and $122.2 \mathrm{MtCO}_{2} \mathrm{e}$ was due to the transport industry, with $74 \%$ of this figure due to cars, taxis and busses (Dft, 2010). Due to the aforementioned negative environmental impacts of emissions from fossil fuel energy sources, this figure needs to be dramatically reduced not only to meet government targets, but for the health of the biosphere. There are some technologies that can be used as alternatives to the fossil fuel dependent transport industry and alleviate our negative impact upon the environment. Battery electric vehicles (BEV) have increased in popularity in recent times due to their potential to have zero emissions (when charged with renewable power sources). However they have not been very popular due to their small ranges and long recharging time requirements (Bernardi \& Verbrugge, 1992). These negative attributes have affected their uptake with the general public customer base, and stinted their growth and commercialization.

Hydrogen fuel cells (HFC) negate the above issues as they are an electro-chemical, zero-emission energy conversion and power generation device. Their only exhaust emission is water. They can be re-fuelled in a similar time to conventional Internal Combustion Engine (ICE) vehicles, and can operate to a similar range. These positive attributes have put the HFC in the limelight as an attractive alternative to the fossil fuel dependant ICE.

\subsection{Fuel Cell Research}

Out of the many classifications of hydrogen fuel cells, the Polymer Electrolyte Membrane Fuel Cell (PEMFC) is commonly singled out as the most appropriate to be implemented into an automotive application. This is due to its relatively low operating 
temperature of around $50-80^{\circ} \mathrm{C}$, its ability to use air as the cathode reactant and its rapid start-up time. Hence the PEMFC is the focus of this paper.

At present, degradation and lifetime analysis of the PEMFC is sparse and still underdeveloped. Although overall reliability analysis of PEMFCs is lacking in development, component level degradation data is somewhat abundant in the Fuel Cell (FC) arena. There are many useful review papers (De Bruijn, et al. 2008; Yousfi-Steiner, et al. 2008; Wu, et al. 2008; Wang, et al. 2012) that identify the possible failure modes of a PEMFC and links to the experiments that suggest an associated degradation rate for the component.

There are certain examples of research that have aimed at addressing the holistic modelling of a PEMFC system. Rama, et al. (2008) constructed a Fault Tree (FT) of a PEMFC at a qualitative level containing no data analysis. It was structured in such a way as to segregate the top failure event into the main loss pathways in a fuel cell; Activation losses, Mass Transportation losses, Ohmic losses, Fuel Efficiency losses and Catastrophic cell failure. This split the overall analysis into five separate trees to represent the ways in which a FC can fail. As no quantitative data was used in this model the tree can be used to gain a greater understanding of the failure characteristics of a FC.

Placca and Kouta (2011) constructed a quantitative FT of a PEMFC using aggregated data from the literature to be used to predict the lifetime of a PEMFC. They split the top event of 'degradation of the cell' into physical components associated with a PEMFC; Membrane, Gas Diffusion Layer and Catalyst Layer. After constructing the tree, they inputted failure and degradation data from numerous sources to predict the lifetime of a cell. A potential limitation of this method of data gathering is that experimental results seldom use the same materials, operating conditions and parameters.

FT analysis (FTA) was most recently used in relation to PEMFC by Yousfi-Steiner, et al. (2012). Previously the authors had looked into using FTA for the water management issues related to a PEMFC (Yousfi-Steiner, et al. 2011), however the recent work took a more systemic level approach. The authors used FTA to model a FC stack and its auxiliary components such as air blowers and piping. However the stack tree was somewhat rudimentary and did not split the FC down into basic events such as in the trees of Rama (2008) and Placca \& Kouta (2011). Even though the latest work was more systemic, it overlooked the basic events that could cause a reduction in stack voltage output which is an area that needs to be developed.

Wieland, et al. (2009) used Petri-net modelling techniques to try to accurately predict the lifetime of a PEMFC stack of a fleet of cars, incorporating Monte Carlo simulation techniques. The model can take into account reversible events, spontaneous events and repairable items. As with the aforementioned FT work, failure and degradation data was taken from the literature to input into the model. The model presented can be quickly and easily adapted to new situations during operation, where new transitions can be freely added. However the authors state in their concluding remarks that a lot of simplifications had to be undertaken to achieve this model. A step forward would be to address the simplifications and to map operating time realistically, which would allow for an availability analysis to be undertaken.

Thus evidence from the research indicates that the current level of research relating to reliability analysis and lifetime prediction requires advancement. FTA is known for being most suited to simple systems with no dependencies between failure modes and interlinked relationships. Petri-Net analysis can take dependencies into account, however it is a lot more complex than FTA and involves a lot more computing time in comparison. Even though there is a multitude of FC degradation experimental data available, it is seldom uniform and directly comparable to other data sets.

The contribution of this paper is in the advancement of the understanding of the failure characteristics of FC, via using FTA. The paper builds upon previous FT work by Placca and Kouta (2011), utilizing the authors' basic outlay to develop the tree. The basic events are updated and built upon to take into account all basic events in a PEMFC. The logic is altered in numerous circumstances to create a more feasible logic structure of PEMFC degradation mechanisms. Issues have been identified, with a future direction for resolution, with regard to certain relationships that exist between basic events in the FC.

\section{PEMFC}

\subsection{Components of a Fuel Cell}

A PEMFC is comprised of four main physical components (shown in figure 1). At the centre is a Polymer Electrolyte Membrane which allows the passage of protons but blocks electron flow. At either side of the central membrane is the Catalyst Layer, which facilitates the breaking down of Hydrogen and Oxygen atoms into protons and electrons at their respective electrodes. A Gas Diffusion Layer is then layered at either side which acts as a conductor of charge and diffuses the inlet gasses to spread evenly on the catalyst layer. Finally the assembly is sandwiched together with the Bipolar Plates. These collect the current from the reactions and transports the electrons to the external circuit, shown by 'Load'. 


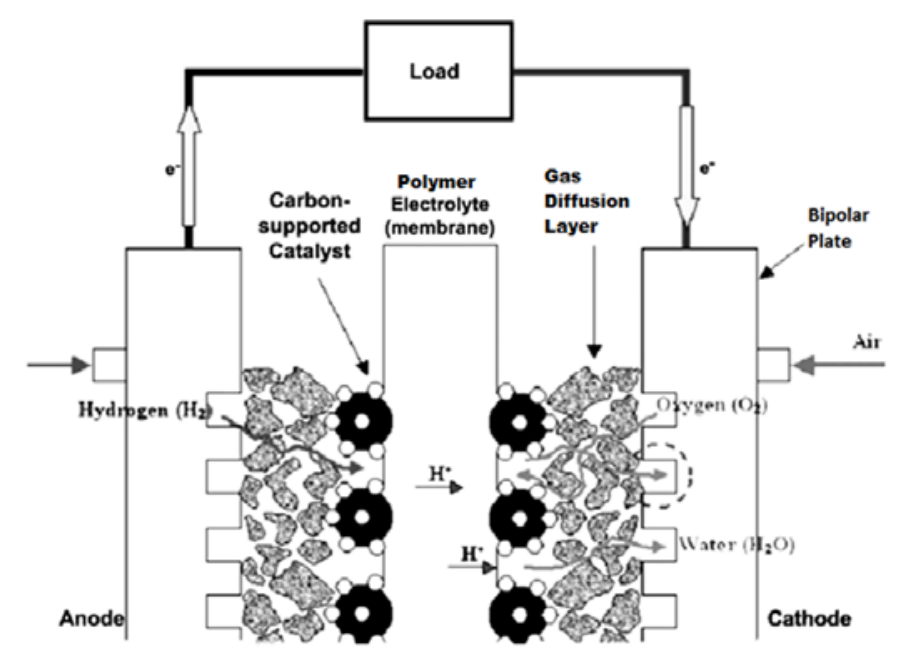

Figure 1. PEMFC components, adapted from Kandlikar \& Lu (2009)

\subsection{Current PEMFC issues}

Currently there are three main hurdles to the commercialisation of PEMFCs and their competition with the ICE, these are; infrastructure, cost and durability ( $\mathrm{Wu}$, et al. 2008). PEMFC durability issues can be mitigated against through reliability analysis techniques. Degradation of a PEMFC is therefore a prominent area for extensive research to aid in the goal of commercialising the PEMFC car.

Degradation in a PEMFC is measureable via a reduction in output voltage (Wang, 2012). Current lifetime goals accepted by the fuel cell community state that a fuel cell in an automotive application must operate for 5000 hours with a reduction in output voltage of no more than $5 \%$ over the 5000 hours period. This gives a solid indicator and timeframe for the measurement of undesirable degradation in a PEMFC and the performance measure for reliability quantification.

\subsection{State of the art for FTA of PEMFCs}

Fault trees have been used by some researchers to try to gain a greater understanding of the component failure mode combinations that contribute to the failure of the PEMFC itself. The work by Placca and Kouta (2011) is the most up-to-date FT of a PEMFC. Previous attempts had been developed at a qualitative level (Rama, et al. 2008) and these have been built upon in the subsequent studies. Hence the research presented in this paper has focussed on the latest work, involving a comprehensive evaluation leading to further developments.

The work by Placca and Kouta (2011) used FT analysis to investigate PEM fuel cell degradation. A FT of a single cell PEMFC was constructed with the overall concerning factor being the top event of 'Degradation of the cell' to an extent that was detrimental to the functioning of the PEMFC system.
They used reliability data compiled from many sources within the literature, and extrapolated the data to acquire a formatted degradation measure that was standardised to alleviate differences in test protocols. From various literary sources, the conclusion drawn was that there were 37 individual basic events to be considered when analysing the degradation of a PEMFC. The FT presented is a 'physical' analysis of a single cell PEMFC, splitting the top-event down through an OR gate into three physical components of a PEMFC (as shown in figure 2):

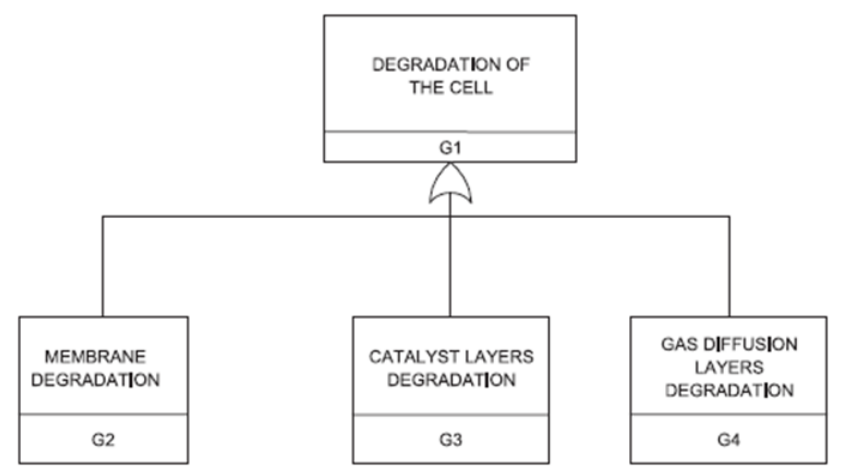

Figure 2. 'Global' Fault Tree presented by Placca and Kouta (2011)

\subsection{Limitations found in FTA}

Though the most recent FT in the literature is a step forward in the degradation analysis of PEMFCs at a system level, research into the tree has revealed limitations that need to be further evaluated. Three main areas have been identified, these being: event clarification, missing failure modes and relationship concerns.

In terms of event clarification, the top event and some intermediate and basic events were found to be equivocal. Steps to define these basic events and intermediate events more clearly was found necessary.

Given that degradation of a cell follows a continuous spectrum, the top event of 'Degradation of the Cell' should be given greater clarity. As it stands it does not state whether the degradation is catastrophic, or whether the rate is undesirable. Therefore improvements can be made by extracting the information from requirements set out by the U.S. Department of Energy (DOE) for an automotive fuel cell to achieve a lifetime of 5000 hours (equivalent to 150,000 miles average) with no more than a $5 \%$ drop in performance throughout the 5000 hours. Other requirements set by the Japanese and European respective departments suggest the same 5000 hour lifetime goal by 2015 .

Missing aspects primarily related to the Bipolar Plate (BIP), an aspect of a PEMFC which was omitted. For a complete system level analysis, this needs to be re-introduced, as two main degradation mechanisms regarding the BIP (metal ion release \& oxide film formation) not only have a dramatic re- 
duction in voltage output locally, they can have adverse effects in other areas of the cell.

The relationship issue identified is with the inherent complexity of the PEMFCs operational kinetics, which yield subsequent relationships between basic events. The analysis undertaken in this study has shown how some events that have previously been listed as basic events with a straight forward relationship to the top event, were in fact quite complex issues involving influences from other basic events and operating conditions exist. Improvements in the logic in the earlier tree have been found, where areas involving intermediate and basic events need to be modified and exchanged in order to rationalise the logic of the degradation mechanisms.

\section{PROPOSED ENHANCED FT}

This paper aims to address the limitations found with the previous FTA and assesses the feasibility of incorporating other reliability techniques to alleviate the key issues.

\subsection{Top Event and Level 1 structure}

The FT constructed has the top event ' $<5000 \mathrm{~h}$ cell lifetime with $>5 \%$ drop of output voltage', using the Department of Energy's performance requirements.

The FT was initiated by segregating out the four main components of a PEMFC, giving the intermediate events in Level 1 of the structure as shown in figure 3 .

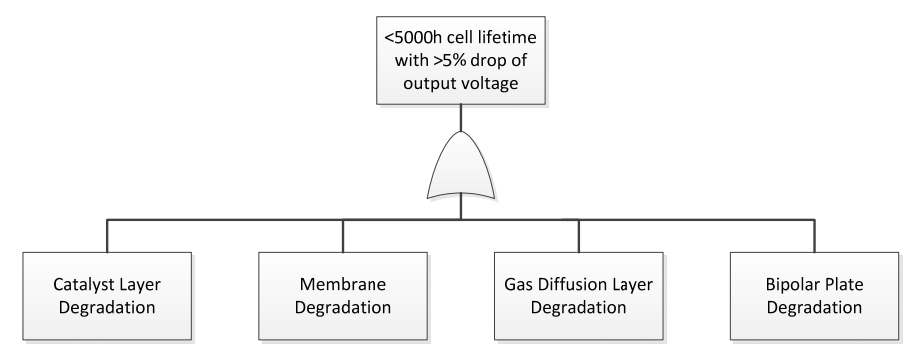

Figure 3. 'Global' Fault Tree proposed

\subsection{Component Failure Mode Evaluation}

\subsubsection{The Modes}

Following investigation into the operation of the PEMFC, along with a FMEA to understand the effect of the component failure modes, 23 basic events were found relating to the top event ' $<5000 \mathrm{~h}$ cell lifetime with $>5 \%$ drop of output voltage', and for which data is available for a quantitative analysis.

The basic events for each section of the four Level 1 intermediate events are shown in Table 1 . Some of the basic events listed in this table were not considered in previous work using FTA, however they have been introduced in this work as the literature shows that these failure modes have been observed in PEMFC operation. The failure modes that have remained unchanged from previous studies are listed in bold text.

Table 1. List of basic events

Basic Events for Intermediate Event - Membrane Degradation

Pinholes due to mechanical stress

Creep

\section{Flooding}

Ice Formation

Oxide Film-Formation

Fatigue from Relative Humidity and Temp Cycling

Dissolution of Metal Ions

Contaminant (various sources - Platinum-Pt, Iron-Fe etc)

Formation of amid acid structures

Formation of amine and diacid terminal groups

Normal Gas Permeability

Previously formed Pinholes

$\mathrm{H}_{2} \mathrm{O}_{2}$ (Peroxide) Formation

$\mathrm{H}_{2} \mathrm{O}_{2}$ Created from 2 electron reduction of $\mathrm{O}_{2}$ on $\mathrm{Pt}$

Excess Heat

Basic Events for Intermediate Event - Catalyst Degradation

Pt Agglomeration Dissolution

$\mathrm{Pt}$ loss and distribution

Pt migration

Dissolution of Metal Ions

Contaminant from Humidifier/air pipe and Gas impurities

Startup/Shutdown-Cycling

Flooding

Ice Formation

Ionomer Degradation

Basic Events for Intermediate Event - Gas Diffusion Layer

OH Radicals

Interfacial delamination due to freeze/thaw cycling

Flooding

Voltage Oxidation

Lower RH of reactant

Mechanical Compression

Basic Events for Intermediate Event - Bipolar Plate

Dissolution of metal ions

Oxide Film Formation

The main modification of the basic events from previous research is mainly due to the realisation that most events could be further split down into lower level basic events. To illustrate an example of the type of modification required, with reasoning, the issue of Radicals is discussed.

\subsubsection{Mode Modifications - Radicals}

One example is the 'Formation of $\mathrm{OH}$ and $\mathrm{OOH}$ radicals'. $\mathrm{OH}$ and $\mathrm{OOH}$ radicals are caused by the chemical changes brought around due to $\mathrm{H}_{2} \mathrm{O}_{2}$ (peroxide) presence. As such, $\mathrm{H}_{2} \mathrm{O}_{2}$ formation from its two main pathways (diffusion and electron reduction) are put forward as basic events leading to $\mathrm{OH}$ and $\mathrm{OOH}$ radical formation as an intermediate event. To further explain the pathways, LaConti, et al. (2003) proposed a method of production of radicals, which occurs due to the diffusion of gasses through the membrane.

$$
\begin{aligned}
& \mathrm{H}_{2} \rightarrow 2 \mathrm{H}^{-} \\
& \mathrm{H}^{-}+\mathrm{O}_{2} \rightarrow \mathrm{HO}_{2} \\
& \mathrm{HO}_{2}^{\cdot}+\mathrm{H}^{\cdot} \rightarrow \mathrm{H}_{2} \mathrm{O}_{2}
\end{aligned}
$$




$$
\begin{aligned}
& \mathrm{H}_{2} \mathrm{O}_{2}+\mathrm{M}^{2+} \rightarrow \mathrm{M}^{3+}+\mathrm{OH}+\mathrm{OH}^{-} \\
& \mathrm{OH}+\mathrm{H}_{2} \mathrm{O}_{2} \rightarrow \mathrm{H}_{2} \mathrm{O}+\mathrm{HO}_{2} \cdot
\end{aligned}
$$

Equations 1-5 show the stages of how radicals are a product of $\mathrm{H}_{2} \mathrm{O}_{2}$ production which occurs under normal operating conditions and membrane health. Therefore $\mathrm{H}_{2} \mathrm{O}_{2}$ needs to be included as the basic event leading to radical formation.

Pozio, et al. (2003) suggest that peroxide can form, by equation 6 , by a 2 electron reduction of $\mathrm{O}_{2}$ pathway;

$$
\mathrm{O}_{2}+2 \mathrm{H}^{+}+2 \mathrm{e}^{-} \rightarrow \mathrm{H}_{2} \mathrm{O}_{2}
$$

Due to the equation $6, \mathrm{OH}$ and $\mathrm{OOH}$ radicals were modified into an intermediate event with inputs from two basic events; ' $\mathrm{H}_{2} \mathrm{O}_{2}$ Formation', which represents the formation under normal conditions, and ' $\mathrm{H}_{2} \mathrm{O}_{2}$ created from 2 electron reduction of $\mathrm{O}_{2}$ on Pt' (shown in figure 4).

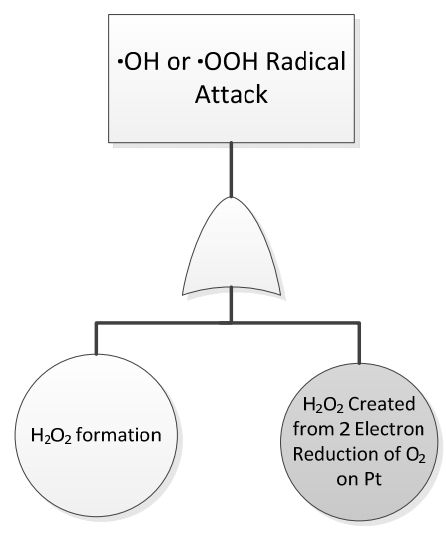

Figure 4. Modified Radical Logic

\subsection{Fault Tree Summary}

The Level 1 intermediate events are themselves broken down further. The Level 1 intermediate event 'Gas Diffusion Layer Degradation' is shown in figure 5. The inputs to this event are failures resulting from the Anode side, the Cathode side, and also from Mechanical Compression. Further breakdown of these events yields the full tree, for this section, which has 7 intermediate events and 11 basic event inputs.

In terms of the full tree, there are 70 generic basic events, stemming from 37 intermediate events. The basic events are all connected by OR gates as each basic event can lead to the overall top event individually.

This paper has re-evaluated the previous FT logic including the addition of previously omitted failure modes. It has also identified limitations with using basic FTA as a method to evaluate a PEMFC. The new FT layout is a more logical progression of the failure modes in a PEMFC, and as such is a step forward in the reliability analysis of PEMFC.

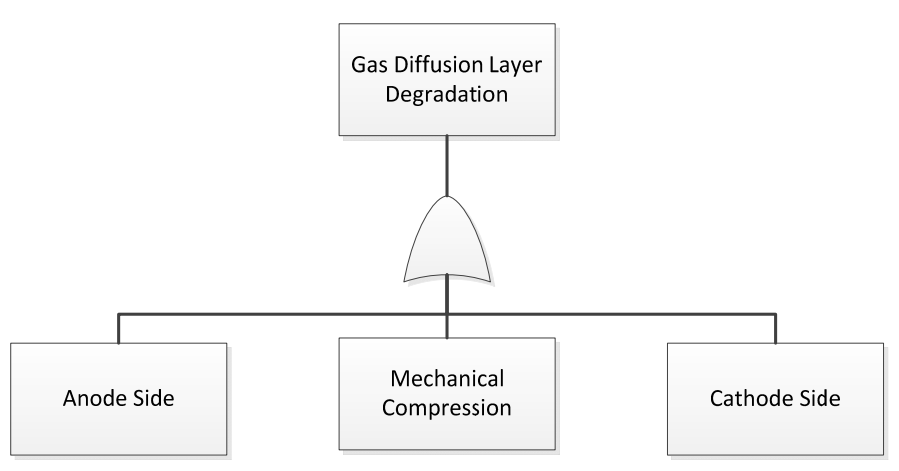

Figure 5. GDL further development.

\section{RELATIONSHIP CONCERNS}

Though the FT presented is an improvement on existing modelling using this technique, by examining the events in the FT it is felt that further advancements can be made with regards to better portrayal of the event interactions. The main concern with the FT approach used to evaluate a PEMFC is the pitfall of intricate relationships. It is seldom the case that one failure mode will be isolated from other failure mode's influences, there are combinations and relationships that could accelerate degradation or mitigate against degradation.

This flags a problem where alternative reliability techniques may need to be exploited. In particular two interactions are discussed, one relating to the effects of Platinum and the second related to Pinholes.

\subsection{Platinum Catalyst Degradation}

One of the main overarching pitfalls regarding relationships between basic events occurs within Platinum (Pt) catalyst degradation. The catalyst layer is comprised of a fine distribution of $\mathrm{Pt}$ nanoparticles, dispersed over carbon black support. The catalyst layer is subject to research attention as it is feeds into one of the three main hurdles to commercialisation of fuel cells; cost. Pt is a fundamentally expensive metal and the most effective way to utilise this commodity is to reduce the Pt loadings and increase their durability in a cell. The mechanisms for $\mathrm{Pt}$ catalyst degradation are; (i) Agglomeration and Particle Growth; (ii) Loss; (iii) Migration and (iv) Poisoning due to Contamination (shown in figure 6). 


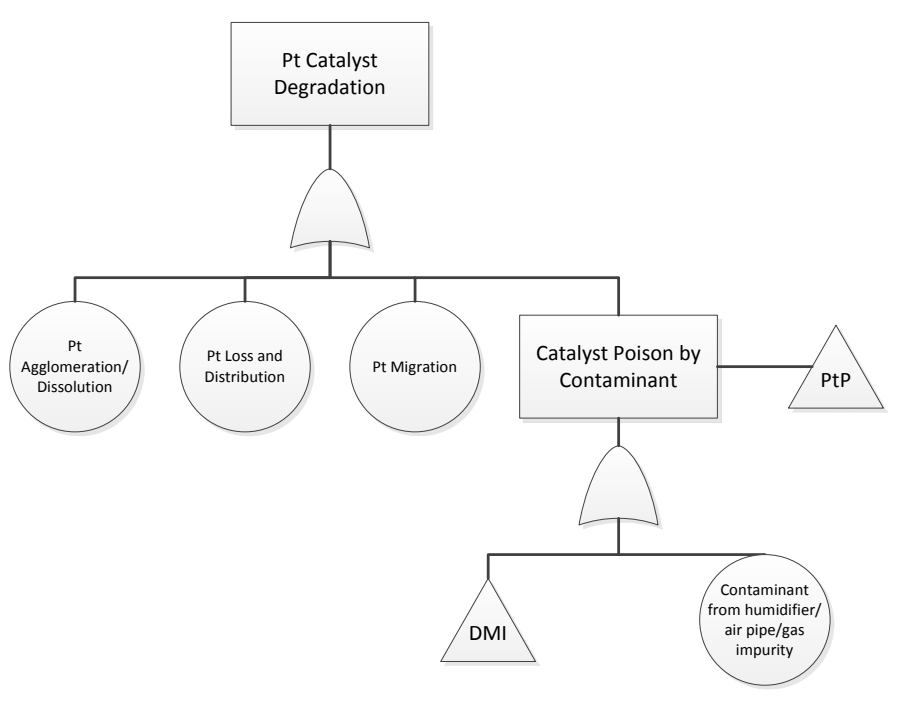

Figure 6. Pt Catalyst Degradation FT logic.

Agglomeration and Particle Growth refers to the tendency for small nanoparticles of $\mathrm{Pt}$ to want to group together and cluster to form larger particles. The thermodynamically driven development is apparent due to larger particles of Pt being more energetically preferential than smaller ones. This mechanism is often referred to as 'Ostwald Ripening'.

Pt Loss is a process where nanoparticles of $\mathrm{Pt}$ can be detached from their carbon support and flow through the fuel cell to be removed by the product water.

Migration is a similar process to Loss, however the detached particles can be redistributed to other areas of the fuel cell, causing adverse effects with other components.

Poisoning due to Contamination can be categorised by the degradation of the catalyst due to foreign contaminants from either fuel supply or systemderived contaminants.

The above mechanisms of degradation will reduce the overall surface area of catalyst and reduce the electrochemically active surface area (ECSA) of the cell. Not only does the loss of ECSA due to the previous degradation mechanisms cause an overall reduction in output voltage, but $\mathrm{Pt}$ particles present in other areas of the fuel cell can cause concerns. In these other area Pt contamination will cause exacerbations in other failure modes. Pt can facilitate the creation of $\mathrm{OOH}$ radicals in the membrane, also leading to $\mathrm{H}_{2} \mathrm{O}_{2}$ formation, by the process denoted in equations $7-9$;

$$
\begin{aligned}
& \mathrm{H}_{2}+\mathrm{Pt} \rightarrow \mathrm{Pt}-\mathrm{H} \\
& \mathrm{Pt}-\mathrm{H}+\mathrm{O} 2 \rightarrow \cdot \mathrm{OOH} \\
& \mathrm{OOH}+\mathrm{Pt}-\mathrm{H} \rightarrow \mathrm{H}_{2} \mathrm{O}_{2}
\end{aligned}
$$

Pt can also act as a catalyst for carbon oxidation which can affect the catalyst support and the GDL. Carbon can be oxidised to form $\mathrm{CO}_{2}$ at relatively low potentials. However the kinetics of this process is so slow, that carbon is fine to use in fuel cell applications. However when Pt is present, it can speed up this reaction to cause cell degradation as per equations $10 \& 11$;

$$
\begin{aligned}
& \mathrm{C}+\mathrm{H}_{2} \mathrm{O} \rightarrow \mathrm{CO}+2 \mathrm{H}^{+}+2 \mathrm{e}^{-} \\
& \mathrm{CO}+\mathrm{H}_{2} \mathrm{O} \rightarrow \mathrm{CO}_{2}+2 \mathrm{H}^{+}+2 \mathrm{e}^{-}
\end{aligned}
$$

Equation 11 uses Pt to catalyse the reaction forming $\mathrm{CO}_{2}$ from the Carbon material in the fuel cell. The presence of Pt particles reduces the potential region from $1.1 \mathrm{~V}$ vs reversible hydrogen electrode (RHE) for carbon corrosion, to $0.55 \mathrm{~V}$ vs RHE. The fuel cell is far more likely to be operating at the lower voltage and as such poses a significant risk of performance loss.

\subsection{Pinholes and their Formation}

Pinholes are a mechanical deformation of the membrane (as shown in figure 7). Pinholes, from previous research, were cited as three separate basic events explained as; (i) Pinholes Production (mechanical degradation); (ii) Pinholes (due to exothermal combustion between $\mathrm{H}_{2}$ and $\mathrm{O}_{2}$ ); (iii) Formation of Pinholes (due to contamination by trace metal ion). These failure modes were adapted to fit logically into the new tree (examples shown in two sections of the new tree in figure 8), however further analysis has identified a potential issue with this failure mode.

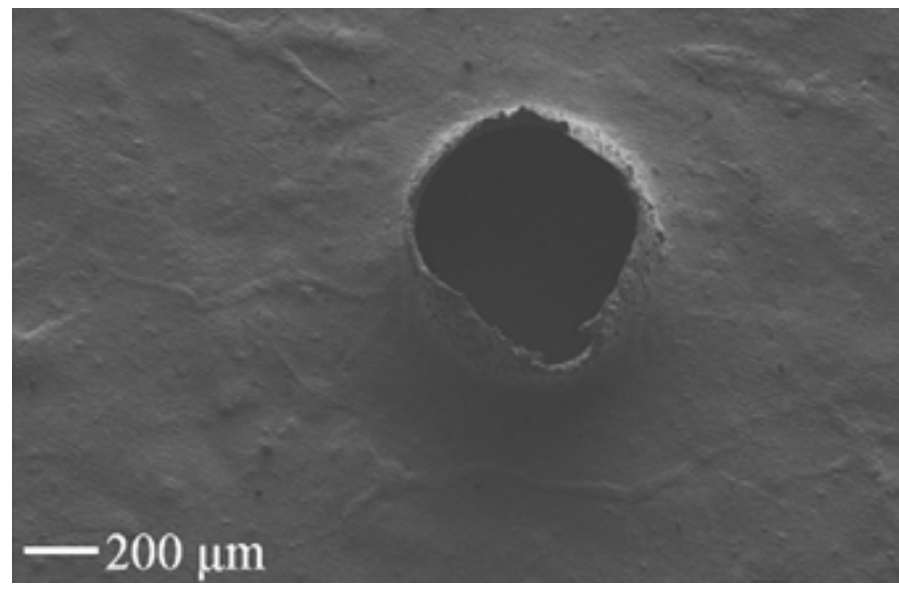

Figure 7. Example of Pinholes in PEMFC membrane. (Huang, et al. 2013)

Pinholes pose a drawback when utilising FTA for PEMFC degradation modelling, through its cyclic behaviour (shown in figure 9). Pinholes can be created through the exothermal combustion of $\mathrm{H}_{2}$ and $\mathrm{O}_{2}$ which comes around from reactant gas crossover. This is not the only chemical attack phenomenon that can lead to pinholes. Chemical attack of any kind causes membrane thinning, which increases the risk of pinholes. Once a pinhole has propagated through this process, more gas is allowed to cross over, resulting in more combustion of gases, causing 
hot spots and consequently more pinholes. This vicious cycle starts an exponential decay or PEMFC performance.

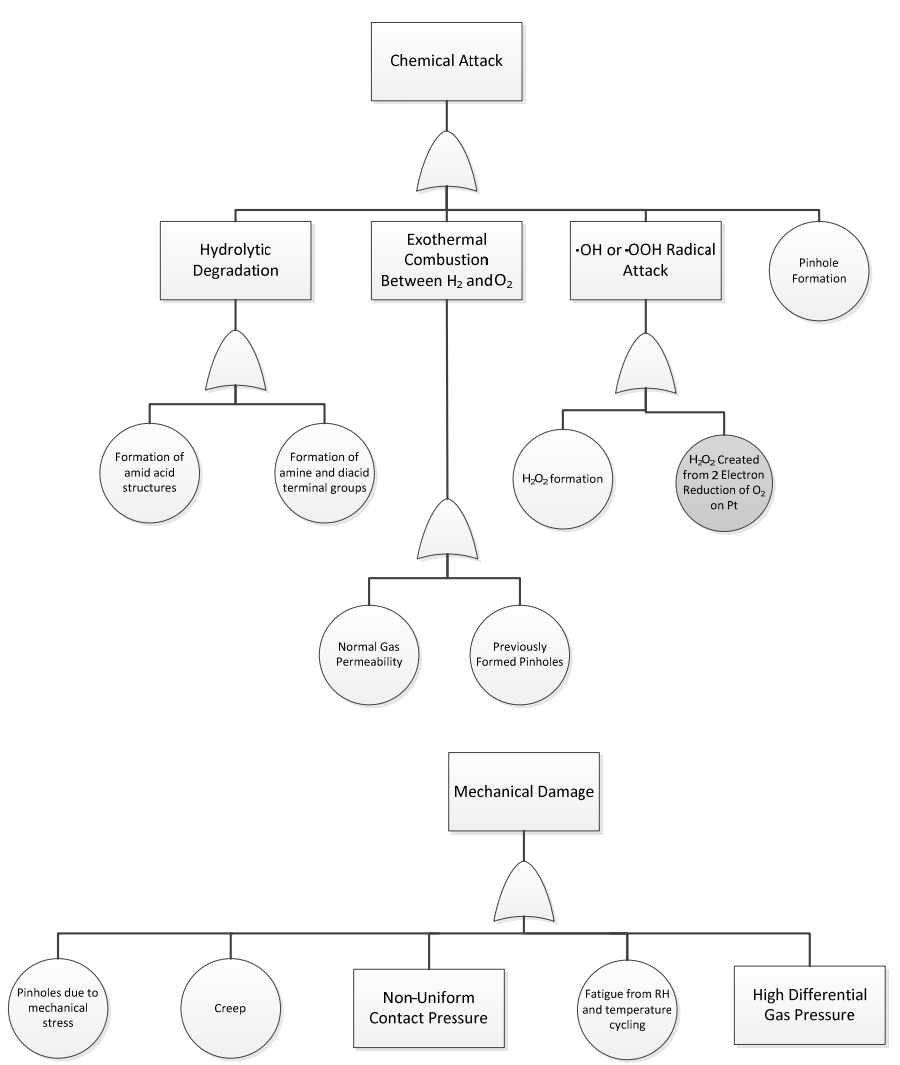

Figure 8. Pinholes logic within chemical and mechanical branches

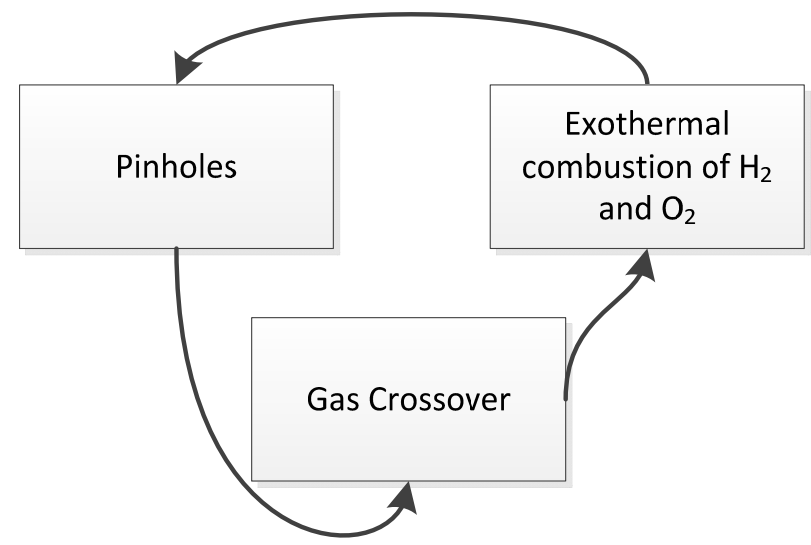

Figure 9. Pinholes cycle.

Currently this behaviour is not modelled within the fault tree structure, and it is suggested for a more accurate model of the PEMFC degradation mechanisms to be evaluated using advanced reliability techniques, which would be incorporated into the FT, adapting the current structure.

\subsection{Suggested Ways Forward}

The main issue found with using FTA to evaluate a PEMFC is regarding the relationships between basic events. The PEMFC system cannot be split into individual basic events that are isolated in nature. Examples have been noted where the interaction be- tween two failure modes can increase or decrease the rate of degradation observed.

Incorporating different reliability techniques could rectify the highlighted issues and this needs to be explored in relation to PEMFC analysis to assess their feasibility of use.

Given that there are functional and sequence dependencies between certain fuel cell failure modes, one method that could be used to tackle these is to separate out the different elements of the FT. Markov Modelling can be used to incorporate dependencies within the fault tree, however these need to be used in isolated regions of the tree that have no repetition in other areas of the tree. The non-dependent elements would be analysed in the normal FT manner, with the identified dependent sub-trees analysed using Markov methods. It is only feasible to use this technique on a portion of the tree due to the problem of the exponential growth of the size of the model. Current concerns with this method is the inability to identify distinct states in the model in which knowledge is known of the rates of transitions between the states, such is the current lack of knowledge at component level for these transitions.

Other possible techniques that could be adopted are digraphs and dynamic fault trees. The dynamic fault tree is a fault tree, which is extended with the time requirements. The digraph method has been identified as a possible solution where loops in the relationships exist.

It is planned that these methods will now be evaluated to determine their feasibility to address the previously highlighted issues with the basic FTA approach to PEMFC analysis.

\section{CONCLUSIONS}

To increase the lifespan and to reduce the risk of failure in PEMFC, reliability analysis techniques such as FTA can be used to gain a greater understanding of the failure modes in a PEMFC and their relationships. In this work a more accurate FT of the degradation of a PEMFC than has previously been presented in the literature has been developed. By gaining a greater understanding of the relevant basic events, and their interactions, a more comprehensive FT has been formulated, giving a breakdown of the top event into a multitude of intermediate events and clearly defined basic events. Though the generated FT model is a more accurate representation of the PEMFC degradation event further enhancements that are necessary have been identified through the research, involving more detailed modelling of current component interactions. The use of an integrated Markov modelling approach is a suggested way forward to tackling the issues where dependencies have been identified. Future work will include the appraisal of advanced reliability techniques, to alleviate the found issues with basic FTA applied to 
a PEMFC. Specifically the pinhole issue needs to be assessed in detail, alongside instances of failure mode exacerbation upon other events in the cell.

\section{References}

BERR. (2012) 2011 UK Greenhouse Gas Emission, Provisional Figures and 2010 UK Greenhouse Gas Emissions, Final Figures by Fuel Type and End-User. [report] available from:

http://webarchive.nationalarchives.gov.uk/t/http:/www.berr.go v.uk/files/file35874.pdf

Bernardi, DM \& Verbrugge, MW. (1992) Mathematical model of the solid-polymer-electrolyte fuel cell. [journal] 139(9):2477-91

De Bruijn, FA. Dam, VAT \& Janssen, JM. (2008) Review: Durability and Degradation issues of PEM fuel cell components. [journal] 8(1):3-22

DfT (2010) UK Transport Greenhouse Gas Emissions. [report] in Department for Transport, available from: $<$ http://assets.dft.gov.uk/statistics/series/energy-andenvironment/climatechangefactsheets.pdf $>$

Gulati, R. \& Dugan J. (1997) A modular approach for analyzing static and dynamic fault trees. Proceedings of the Annual Reliability and Maintainability Symposium, pages 1-7.

Huang, BT. Chatillon, Y. Bonnet, C. Lapicaque, F. Leclerc, S. Hinaje, M \& Rael, S. (2013) Experimental investigation of pinhole effect on MEA/cell aging in PEMFC. [journal] 38(2013):543-550.

LaConti, AB. Hamdan, M. McDonald, RC. Vielstich, W. Lamm, A \& Gasteiger, H. (2003) Handbook of Fuel Cells: Fundamentals, technology, and applications.[book] $3^{\text {rd }} \mathrm{Ed}$, Chichester, England:Wiley.

Placca, L. Kouta, R. (2011) Fault tree analysis for PEM fuel cell degradation process modelling. [journal] 2011;36(19):12393-405.

Pozio, A. Silva, RF. De Francesco, M \& Giorgi, L. (2003) Nafion degradation in PEFCs from end plate iron contamination. [journal] 48(11):1543-9

Rama, P. Chen, R, \& Andrews, JD. (2008) Failure analysis of Polymer Electrolyte Fuel Cells (PEFC). [conference] IN: Proceedings of the SAE 2008, SAE World Congress, Detroit, Michigan, April 14-17.

Solloman, S. (2007) Summary for Policy Makers. [report] in IPCC, available from:

$<$ http://www.lc.unsw.edu.au/onlib/refbib2.html>
Wang, H. Li, H \& Yuan, H. (2012) PEM Fuel Cell Failure Mode Analysis, [book] 1st Ed, Boca Raton, USA:Taylor \& Francis Group.

Wieland, C. Schmid, O. Meiler, M. Wachtel, A \& Linsler, D. (2009) Reliability computing of polymer-electrolyte-membrane fuel cell stacks through Petri nets. [journal] 190(1):34-39.

Wu, J. Zi Yuan, X. Martin, JJ. Wang, H. Zhang, J. (2008) A review of PEM fuel cell durability: Degradation mechanisms and mitigation strategies, [journal] 184(2008):104-119

Yousfi-Steiner, N. Hissel, D. Moçotéguy, P. Candusso, D. Marra, D. Pianese, C \& Sorrentino, M. (2012) Application of fault tree analysis to fuel cell diagnosis. [journal] 12(2):302309.

Yousfi Steiner, N. Hissel, D. Moçtéguy, P. \& Candusso, D. (2011) Diagnosis of polymer electrolyte fuel cells failure modes (flooding \& drying out) by neural networks modeling. [journal] 36(4):3067-3075.

Yousfi-Steiner, N. Moçotéguy, P. Candusso, D \& Hissel, D. (2008) A review on PEM voltage degradation associated with water management: Impacts, influent factors and characterisation. 183(1):260-274 